\title{
Erratum to: Energy Stable Flux Reconstruction Schemes for Advection-Diffusion Problems on Tetrahedra
}

\author{
D. M. Williams • A. Jameson
}

Published online: 23 October 2013

(C) Springer Science+Business Media New York 2013

\section{Erratum to: J Sci Comput \\ DOI 10.1007/s10915-013-9780-2}

In the original publication, the authors would like to correct equations (37) and (119) as follows:

1. The text immediately following Eq. (37) "where $v=1, \ldots, p$ and $w=1, \ldots, v$ " should change to "where $\mathrm{v}=1, \ldots, \mathrm{p}+1$ and $\mathrm{w}=1, \ldots, \mathrm{v} . "$

2. The text immediately following Eq. (119) "where $v=1, \ldots, p$ and $w=1, \ldots, v$ " should change to "where $\mathrm{v}=1, \ldots, \mathrm{p}+1$ and $\mathrm{w}=1, \ldots, \mathrm{v}$."

The online version of the original article can be found under doi:10.1007/s10915-013-9780-2.

D. M. Williams $(\varangle) \cdot$ A. Jameson

Stanford University, Stanford, CA 94305, USA

e-mail: davidmw@alumni.stanford.edu 